\title{
The effects of tranexamic acid on blood loss and transfusion rate in colorectal surgery
}

\author{
Fabian Grass ${ }^{a}$, Signe Braafladt ${ }^{b}$, Jasim Alabbad a, Jenna K. Lovely ${ }^{c}$, Scott R. Kelley ${ }^{\text {a }}$, \\ Kellie L. Mathis ${ }^{a}$, Marianne Huebner ${ }^{\mathrm{d}}$, David W. Larson ${ }^{\mathrm{a},{ }^{*}}$ \\ a Colon and Rectal Surgery, Mayo Clinic, Rochester, MN, USA \\ b St. Olaf College, Northfield, MN, USA \\ ${ }^{\mathrm{c}}$ Mayo Clinic Pharmacy, Rochester, MN, USA \\ d Biostatistics, Mayo Clinic, Rochester, MN, USA
}

\section{A R T I C L E I N F O}

\section{Article history:}

Received 6 February 2019

Received in revised form

11 March 2019

Accepted 13 March 2019

\section{Keywords:}

Tranexamic acid

Colorectal surgery

Patient outcomes

\begin{abstract}
A B S T R A C T
Background: The present study aimed to evaluate safety of tranexamic acid (TA) administration and to assess bleeding risk in colorectal surgery (CRS).

Methods: Retrospective cohort study including consecutive patients undergoing elective CRS by a single surgeon between August 2014 and May 2015. All patients received $1 \mathrm{~g}$ of TA intravenously at induction and at closure. Demographics, operative and postoperative details were prospectively assessed and compared to a historical control cohort.

Results: 213 patients were evaluated. TA did not increase complications, readmissions, or reoperation rates. Significant postoperative hemoglobin (Hgb) drop ( $\geq 3 \mathrm{~g} / \mathrm{dL})(\mathrm{TA}: \mathrm{n}=6,7.4 \%$, Control: $\mathrm{n}=22,16.6 \%$; $\mathrm{p}=0.193$ ) and transfusion rates (intraoperative: TA: $\mathrm{n}=2,2.5 \%$, Control: $\mathrm{n}=2,1.5 \%$; $\mathrm{p}=0.586$, postoperative: TA: $\mathrm{n}=1,1.2 \%$, Control: $9,6.8 \% ; \mathrm{p}=0.065)$ were not statistically different.

Conclusions: Postoperative hemoglobin drop and transfusion rates were not decreased statistically. Further study is warranted given the large clinical differences in favor of TA.
\end{abstract}

(C) 2019 Elsevier Inc. All rights reserved.

\section{Introduction}

Perioperative blood transfusions are associated with several risks including immunological complications, higher rates of postoperative infections, prolonged hospitalization, and a potential to increase cancer recurrence. ${ }^{1-4}$ A shortage of blood products throughout the nation creates negative logistical and health system pressures. ${ }^{5,6}$ One could significantly impact the cost and quality of care if blood transfusions can be safely avoided. ${ }^{7}$

Fibrinolysis regulates the balance of clot formation and degradation by promoting the generation of plasmin, via plasminogen, which leads to the breakdown of fibrin, fibrinogen, and eventually clot. $^{8}$ This pathway is commonly targeted in an attempt to decrease bleeding and resultant blood transfusions. Historically, aprotinin, an antifibrinolytic drug, was effective at decreasing blood loss in surgical patients, but secondary to cardiac complications and

\footnotetext{
* Corresponding author. Division of Colon and Rectal Surgery, Mayo Clinic, 200 First Street SW, Rochester, MN, 55905, USA.

E-mail address: larson.david2@mayo.edu (D.W. Larson).
}

mortality it was pulled from the market in $2008 .{ }^{9,10}$ Alternative approaches are needed in order to positively impact patients, hospitals, and health care quality and economics related to blood loss and transfusions.

Tranexamic acid (TA) is a lysine analog that inhibits the degradation of fibrin and fibrinogen by reversibly blocking lysine binding sites on plasmin and plasminogen. ${ }^{11,12}$ Recent systematic reviews and meta-analyses have shown that TA decreases blood loss and transfusion requirements in cardiac, orthopedic, and gynecologic procedures. ${ }^{13-16}$ In more than 20,000 trauma patients, TA significantly reduced the risk of death from bleeding. ${ }^{17}$ A recent randomized trial however failed to demonstrate blood loss reduction or improved clinical outcomes in patients admitted to the hospital with lower GI hemorrhage. ${ }^{18}$ Transfusion rates for colon and rectal surgeries range from 5 to $10 \%$, though the ability of TA to affect perioperative blood transfusions and blood loss has not been studied. ${ }^{19}$

The purpose of this pilot study was to determine if TA can be safely administered while reducing blood loss and transfusion risk in patients undergoing colorectal surgery. 


\section{Material and methods}

Using a prospectively maintained database, a retrospective review of all elective colon and rectal surgeries performed by one colorectal surgeon (D.W.L) using TA between August 2014 and May 2015 was performed and compared to a control cohort treated without TA (November 2013 to August 2014). One gram of TA was administered intravenously at the beginning (induction of anesthesia) and end (skin closure) of surgery. All patients older than or equal to 18 years of age were candidates for study eligibility. Exclusion criteria included age younger than 18 years, preoperative use of anticoagulants by the time of inclusion, emergency operations, and multidisciplinary procedures with additional organ resection. The Mayo Clinic Institutional Review Board approved this study and all patients provided informed consent before enrollment. Only institutional funds were used to conduct this study.

Institutional standardized guidelines dictated intraoperative transfusions for hemodynamic compromise and/or significant intraoperative blood loss with a hemoglobin (Hgb) level less than $7 \mathrm{~g} / \mathrm{dL}$. Postoperatively, a significant decrease in $\mathrm{Hgb}$ was defined as $\mathrm{a} \geq 3 \mathrm{~g} / \mathrm{dL}$ drop within $24 \mathrm{~h}$ of surgery compared to the preoperative (baseline) level (= perioperative $\mathrm{Hgb}$ change). Postoperative transfusions were administered for $\mathrm{Hgb}<7 \mathrm{~g} / \mathrm{dL}$, or Hgb less than $8 \mathrm{~g} / \mathrm{dL}$ with signs of systemic compromise (heart rate $>120 \mathrm{bpm}$, systolic blood pressure $<100 \mathrm{mmHg}$, orthostatic hypotension, or dizziness and/or a fall). Estimated blood loss (EBL) in the operating room was documented by the surgical team at the end of the procedure and stratified into three tiered groups $(0-250 \mathrm{ml}$, $250-500 \mathrm{ml},>500 \mathrm{ml}$ ). Of note, according to institutional guidelines, all patients received DVT prophylaxis (5000 units of heparin SC at induction and while hospitalized ( $\geq 50 \mathrm{~kg}$ : $3 \mathrm{x} /$ day, $<50 \mathrm{~kg}: 2 \mathrm{x} /$ day)).

Data were prospectively collected by the surgical care team and registered in a dedicated institutional database and included baseline demographics, body mass index (BMI), American Society of Anesthesiologists (ASA) score, smoking status, presence of diabetes, history of pulmonary embolism (PE)/deep venous thrombosis (DVT), both of which were confirmed by board-certified radiologists. Indication for surgery including active medications, type of procedure (partial (left, right or transverse) colectomy, total colectomy, rectal resection (including abdominoperineal resection and low anterior resection) and other (including pouch surgery and ostomy procedures) 30 day postoperative complications according to National Surgical Quality Improvement Program (NSQIP) guidelines and definitions, ${ }^{20}$ and transfusion requirements (units of administered packed red blood cells) were recorded.

In a second step, identical items as specified above were abstracted by the same surgical care team from the institutional database to constitute the control group, which consisted of consecutive patients operated by the same surgeon (D.W.L.) between November 2013 and August 2014, with previously defined inclusion and exclusion criteria.

\section{Statistical methods}

Continuous variables were examined with histograms and summarized with mean and standard deviation or median and interquartile range for symmetric or skewed distributions, respectively. Categorical variables were described with frequencies and percentages. The comparisons of continuous variables between the control and TA groups were performed with nonparametric tests (Mann-Whitney) or two sample t-tests as appropriate. For categorical variables Fisher's exact test was used. Comparisons for small samples with sparse structures (transfusions) were performed using Firth's penalized likelihood procedure that corrects for bias. ${ }^{21}$ All analyses used R v. 3.1.2 and JMP. A two-sided p-value less than 0.05 was considered statistically significant.

\section{Results}

A total of 213 patients were identified, of which 81 (38\%) were enrolled to be treated with TA and compared to 132 patients (62\%) treated without TA (control group). Baseline factors, pharmacotherapy, past medical history, and surgical indications of the two groups are displayed in Tables 1 and 2. Compared to the control group, patients treated with TA were older and had higher ASA scores. Other than a larger number of chronic ulcerative colitis (CUC) patients in the control group (23.5 versus $9.9 \%, \mathrm{p}=0.017$ ),

Table 1

Baseline factors.

\begin{tabular}{|c|c|c|c|c|}
\hline & Control & Tranexamic Acid & Total & p-value \\
\hline & $(\mathrm{N}=132)$ & $(\mathrm{N}=81)$ & $(\mathrm{N}=213)$ & \\
\hline Gender & & & & 0.198 \\
\hline Female & $60(45.5 \%)$ & $29(35.8 \%)$ & $89(41.8 \%)$ & \\
\hline Male & $72(54.5 \%)$ & $52(64.2 \%)$ & $124(58.2 \%)$ & \\
\hline Age & & & & 0.004 \\
\hline Mean (SD) & $50.64(17.09)$ & $57.27(15.37)$ & $50.64(15.74)$ & \\
\hline Median (IQR) & $51.50(37.00,63.00)$ & $58.00(50.00,68.00)$ & $54.00(41.00,65.00)$ & \\
\hline Smoker & & & & 0.202 \\
\hline Current & $8(6.1 \%)$ & $9(11.1 \%)$ & $17(8.0 \%)$ & \\
\hline Not Current $^{\mathrm{a}}$ & 124 (93.9\%) & $72(88.9 \%)$ & $196(92.0 \%)$ & \\
\hline Diabetic & & & & 0.820 \\
\hline Yes & 15 (11.4\%) & $9(11.1 \%)$ & $24(11.3 \%)$ & \\
\hline No & $117(88.6 \%)$ & $72(88.9 \%)$ & 189 (88.7\%) & \\
\hline BMI & & & & 0.547 \\
\hline Mean (SD) & $27.18(6.46)$ & $27.31(5.38)$ & $27.23(6.06)$ & \\
\hline ASA & & & & 0.015 \\
\hline 1 & $9(6.8 \%)$ & $2(2.5 \%)$ & $11(5.2 \%)$ & \\
\hline 2 & $99(75.0 \%)$ & $51(63.0 \%)$ & $150(70.4 \%)$ & \\
\hline 3 & $24(18.2 \%)$ & $28(34.6 \%)$ & $52(24.4 \%)$ & \\
\hline Race & & & & 0.418 \\
\hline Caucasian & $123(93.2 \%)$ & 77 (95.1\%) & 200 (93.9\%) & \\
\hline Not Caucasian & $9(6.8 \%)$ & $4(4.9 \%)$ & $13(6.1 \%)$ & \\
\hline
\end{tabular}

\footnotetext{
${ }^{a}$ Not Current includes never and past smokers, BMI Body mass index, ASA Physical status classification system, SD Standard deviation, IQR Intra quartile range.
} 
Table 2

Preoperative medical history and surgical details.

\begin{tabular}{|c|c|c|c|c|}
\hline & \multirow{2}{*}{$\frac{\text { Control }}{(\mathrm{N}=132)}$} & \multirow{2}{*}{$\frac{\text { Tranexamic Acid }}{(\mathrm{N}=81)}$} & \multirow{2}{*}{$\frac{\text { Total }}{(\mathrm{N}=213)}$} & \multirow[t]{2}{*}{ p-value } \\
\hline & & & & \\
\hline \multicolumn{5}{|l|}{ Medical History } \\
\hline On Steroids & $16(12.1 \%)$ & $14(17.3 \%)$ & $30(14.1 \%)$ & 0.315 \\
\hline On Biologics & $10(7.6 \%)$ & $8(9.9 \%)$ & $18(8.5 \%)$ & 0.616 \\
\hline Recent CRT & $35(26.5 \%)$ & $22(27.2 \%)$ & $57(26.8 \%)$ & 1.000 \\
\hline \multicolumn{5}{|l|}{ Indication } \\
\hline Colon Cancer & $13(9.8 \%)$ & $12(14.8 \%)$ & $25(11.7 \%)$ & 0.282 \\
\hline Rectal Cancer & $36(27.3 \%)$ & $23(28.4 \%)$ & $59(27.7 \%)$ & 0.876 \\
\hline Metastatic CRC & $5(3.8 \%)$ & $4(4.9 \%)$ & $9(4.2 \%)$ & 0.733 \\
\hline Crohn's Disease & $23(17.4 \%)$ & $12(14.8 \%)$ & $35(16.4 \%)$ & 0.705 \\
\hline CUC & $31(23.5 \%)$ & $8(9.9 \%)$ & $39(18.3 \%)$ & 0.0169 \\
\hline Diverticulitis & $21(15.9 \%)$ & $16(19.6 \%)$ & $37(17.4 \%)$ & 0.577 \\
\hline Polyps & $7(5.3 \%)$ & $5(6.2 \%)$ & $12(5.6 \%)$ & 0.769 \\
\hline Other & $10(7.6 \%)$ & $10(12.3 \%)$ & $2(9.4 \%)$ & 0.334 \\
\hline \multicolumn{5}{|c|}{ Surgical procedure } \\
\hline Partial colectomy & $59(44.7 \%)$ & $33(40.7 \%)$ & $92(43.2 \%)$ & 0.571 \\
\hline Total colectomy & $7(5.3 \%)$ & $7(8.7 \%)$ & $14(6.6 \%)$ & 0.339 \\
\hline Rectal resection & $50(37.9 \%)$ & $32(39.5 \%)$ & $82(38.5 \%)$ & 0.813 \\
\hline Other & 16 (12.1\%) & $9(11.1 \%)$ & 25 (11.7\%) & 0.824 \\
\hline
\end{tabular}

Totals may add to greater than $100 \%$ due to multiple indications for surgery. CRCcolorectal cancer, CRT-Chemoradiotherapy, CUC-Chronic ulcerative colitis.

there were no differences noted between the two groups regarding medical history, use of medications, smoking status, or indication for surgery and type of surgery. Postoperative complications, reoperations, and readmissions were similar in both groups (Table 3).

Pre- and postoperative Hgb values did not differ between the two groups (TA vs. control): preoperative: $13.04 \pm 1.64 \mathrm{~g} / \mathrm{dL}$ vs.
$12.98 \pm 1.88 \mathrm{~g} / \mathrm{dL}(\mathrm{p}=0.788)$, postoperative: $11.41 \pm 1.46 \mathrm{~g} / \mathrm{dL}$ vs $11.08 \pm 1.86 \mathrm{~g} / \mathrm{dL}(\mathrm{p}=0.146)$. The proportion of patients with a significant postoperative Hgb decrease was not statistically different between the two groups (Table 4).

Overall there were no statistically significant differences in EBL $(p=0.227)$, although there was a higher proportion of patients with minimal blood loss $(0-250 \mathrm{~mL})$ in the TA $(92.5 \%)$ compared to the control group (87.8\%), as well as fewer larger volume losses $(>250 \mathrm{~mL}$ ) in the TA group (5.0\% vs. $12.2 \%$ ) (Fig. 1). A total of 14 patients (6.6\%) received transfusions (4 intra- and 10 postoperatively). Nine patients required transfusion in the control group compared to a single patient in the TA group in the postoperative period. The odds ratio of receiving a postoperative transfusion following treatment with $\mathrm{TA}$ was 0.24 (95\% CI: $0.025-1.08, \mathrm{p}=0.065$, Table 4).

\section{Discussion}

TA is known to reduce bleeding and transfusion requirements in patients undergoing a wide range of surgical procedures. ${ }^{13-15}$ However, the available literature focuses on surgical procedures with higher rates of blood loss and transfusion requirements and to date, colorectal surgery has not been evaluated. This pilot series failed to demonstrate a statistically significant difference in the rate of $\mathrm{Hgb}$ drop or transfusion rate in an unselected consecutive cohort of patients undergoing colorectal resections. Furthermore, TA did not negatively impact postoperative complications.

The clinically relevant findings of a decrease of more than $50 \%$ in large drops in $\mathrm{Hgb}$ and a 4-fold decreased postoperative transfusion rate suggest that further study is warranted. However, these

Table 3

Surgical outcomes of control and TA treated patients.

\begin{tabular}{|c|c|c|c|c|}
\hline & Control & Tranexamic Acid & Total & p-value \\
\hline & $(\mathrm{N}=132)$ & $(\mathrm{N}=81)$ & $(\mathrm{N}=213)$ & \\
\hline \multicolumn{5}{|l|}{ Outcomes } \\
\hline Any Complication & $63(47.7 \%)$ & $39(48.1 \%)$ & $102(47.9 \%)$ & 1.000 \\
\hline Anastomotic Leak & $4(5.3 \%)$ & $0(0.0 \%)$ & $7(3.3 \%)$ & 0.300 \\
\hline Abscess & $17(12.9 \%)$ & $5(6.2 \%)$ & $22(10.3 \%)$ & 0.172 \\
\hline SSI & $2(1.5 \%)$ & $3(3.7 \%)$ & $5(2.3 \%)$ & 0.376 \\
\hline DVT & $1(0.8 \%)$ & $1(1.2 \%)$ & $2(0.9 \%)$ & 1.000 \\
\hline PE & $0(0.0 \%$ & $0(0.0 \%)$ & $0(0.0 \%)$ & NA \\
\hline UTI & $5(3.8 \%)$ & $5(6.2 \%)$ & $10(4.7 \%)$ & 0.514 \\
\hline Neurological & $2(1.5 \%)$ & $1(1.2 \%)$ & $3(1.4 \%)$ & 1.000 \\
\hline Ileus/SBO & $38(28.8 \%)$ & $12(14.8 \%)$ & $50(23.5 \%)$ & 0.071 \\
\hline Stomal Prolapse & $1(0.8 \%)$ & $0(0.0 \%)$ & $1(0.5 \%)$ & 1.000 \\
\hline Number of complications & & & & 0.181 \\
\hline 0 & $69(52.2 \%)$ & $42(51.9 \%)$ & $111(52.1 \%)$ & 0.471 \\
\hline 1 & $43(32.6 \%)$ & $24(29.6 \%)$ & $67(31.5 \%)$ & \\
\hline 2 & 15 (11.4\%) & $15(18.5 \%)$ & $30(14.1 \%)$ & \\
\hline $3+$ & $5(3.8 \%)$ & 0 & $5(2.3 \%)$ & \\
\hline Readmission & $27(20.5 \%)$ & $12(14.8 \%)$ & $39(18.3 \%)$ & \\
\hline Re-operation & $13(9.8 \%)$ & $6(7.4 \%)$ & $19(8.9 \%)$ & 0.631 \\
\hline
\end{tabular}

SSI - surgical site infection, DVT - deep venous thrombosis, PE - pulmonary embolism.

UTI - urinary tract infection, SBO - small bowel obstruction.

Table 4

Transfusion outcomes of control and TA treated patients.

\begin{tabular}{|c|c|c|c|c|c|}
\hline & Control & Tranexamic Acid & Total & OR (95\% CI) & p-value \\
\hline & $(\mathrm{N}=132)$ & $(\mathrm{N}=81)$ & $(\mathrm{N}=213)$ & & \\
\hline $\begin{array}{l}\text { Hgb change }>3 \mathrm{~g} / \mathrm{dL} \\
\text { Transfusion }\end{array}$ & $22(16.6 \%)$ & $6(7.4 \%)$ & $28(13.1 \%)$ & $0.52(0.19-1.27)$ & 0.193 \\
\hline - Intraoperative & $2(1.5 \%)$ & $2(2.5 \%)$ & $4(1.9 \%)$ & $1.64(0.25-10.82)$ & 0.586 \\
\hline - Postoperative & $9(6.8 \%)$ & $1(1.2 \%)$ & $10(4.7 \%)$ & $0.24(0.025-1.08)$ & 0.065 \\
\hline
\end{tabular}

Hgb - hemoglobin, OR - Firth's penalized odds ratio. 


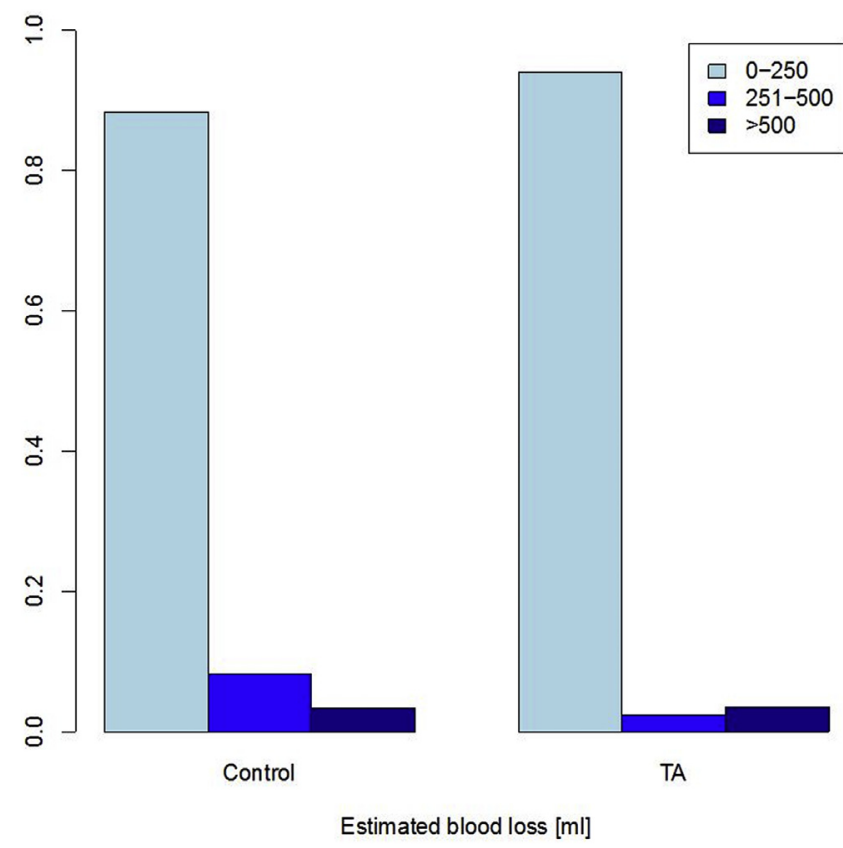

Fig. 1. Proportion of estimated blood loss (EBL) in control and tranexamic acid (TA) treated groups. EBL was measured in milliliters and separated into three categories. There was a higher proportion of patients with lower blood loss in the TA group, and a larger proportion of patients with higher blood loss in the control group ( $\mathrm{p}=0.227$ ).

clinically significant findings need yet to be replicated by larger series, ideally in the setting of a prospective, randomized and adequately powered study. Confirmation of our preliminary findings may represent a significant opportunity for TA to improve quality of care. Furthermore, a significant reduction of postoperative transfusion rates in the field of colorectal surgery could potentially translate in important cost savings for patients and healthcare providers, as previously demonstrated in orthopedic surgery. ${ }^{7}$ Reducing transfusion rates benefit the patient and institution in many ways. Decreasing exposure to transfusions has the potential to reduce inherent risk of nosocomial infection by $50 \%$ in critically ill patients, reduces the risk of lung injury, which remains a rare but potentially serious complication, and avoids immunological issues. ${ }^{22-24}$

There is no standard dosing of TA and multiple regimens have been described. ${ }^{25-27}$ The dosing regimen selected for our population ( $1 \mathrm{~g}$ intravenously at the initiation and end of surgery) was based on institutional experience with orthopedic practice. ${ }^{5}$ This simple dosing regimen was feasible to implement, avoids the cumbersome nature of bolus then infusion regimens and decreases the potential for weight based errors. The meta-analysis by Ker and colleagues (13) showed no additional benefit with doses greater than $1 \mathrm{~g}$. This regimen is well below the various dosing regimens used historically in cardiac surgery which safely avoids the risk of neurologic events leading to seizures seen in with doses exceeding $60 \mathrm{mg} / \mathrm{kg}$ and up to $250 \mathrm{mg} / \mathrm{kg}$. ${ }^{26}$ Even in our extreme low weight patients (30 kg), $1 \mathrm{~g}$ (33 mg/kg) is well below the risk threshold for seizures.

Intraoperative transfusions are typically secondary to technical issues in comparison to the postoperative setting where coagulopathies that promote continued blood loss are more common. We found clinically lower rates of postoperative transfusions in the TA (1.2\%) compared to the control group (6.8\%). Future series within colorectal surgery may thus particularly focus on the role of TA in the postoperative setting.
Ultimately the question colorectal and general surgeons must answer for clinical decision making revolves around the risk versus benefit for particular therapy. This present study was not sufficiently powered or designed to answer all the questions but provides insight into potential benefits of perioperative TA administration in colorectal surgery. No therapy is risk free. If the goal is to reduce transfusions it also means a decreased exposure of patients to known risks, including but not limited to bacterial contamination of platelets (1:2000-3000 transfusions), transfusion errors from patient misidentification $(1: 16,000-19,000)$ and transfusion related acute lung injury $(1: 1000-5000){ }^{23,27}$ The clinical relevance of our series may in fact outweigh the risk of transfusion side effects given no additional risk was identified in patients exposed to TA. In particular, there were no increases in adverse venous thromboembolic events in the TA group, which mirrors other major work in this area, which however requires larger series to assure equivalence. ${ }^{28}$

Limitations to our study include, although are not limited to, its nonrandomized retrospective nature and comparison to a historical control group. Data on unselected, consecutive eligible patients was however prospectively collected over the entire study period, and a uniform approach by a single surgeon (D.W.L.) and singleinstitution were followed to limit selection bias. The small cohort size leaves us with yet inconclusive results due to potential type II error and points toward future prospective studies with adequate sample size calculation (approximately 400 patients) to support these preliminary findings.

\section{Conclusions}

In conclusion tranexamic acid appears to be a safe drug in the setting of colorectal resections. Larger series need to be pursued in a randomized fashion to determine if the clinically significant benefits in our series can be replicated.

\section{Conflicts of interest}

No conflict of interest to declare for all authors.

\section{Author contributions}

Conception and design: FG, SB, JA, DWL.

Acquisition, analysis, interpretation of data: all authors.

Drafting the work or revising it critically for important intellectual content: all authors.

Final approval of the version to be published: all authors.

Agreement to be accountable for all aspects of the work in ensuring that questions related to the accuracy or integrity of any part of the work are appropriately investigated and resolved: all authors.

\section{Funding}

This research did not receive any specific grant from funding agencies in the public, commercial, or not-for-profit sectors.

\section{References}

1. Nielsen HJ. Detrimental effects of perioperative blood transfusion. Br J Surg. 1995 May;82(5):582-587. PubMed PMID: 7613921.

2. Acheson AG, Brookes MJ, Spahn DR. Effects of allogeneic red blood cell transfusions on clinical outcomes in patients undergoing colorectal cancer surgery: a systematic review and meta-analysis. Ann Surg. 2012 Aug;256(2):235-244. PubMed PMID: 22791100.

3. Muller S, Oberle D, Drechsel-Bauerle U, et al. Mortality, morbidity and related outcomes following perioperative blood transfusion in patients with major orthopaedic surgery: a systematic review. Transfus Med Hemotherapy. 2018 
Oct;45(5):355-367. PubMed PMID: 30498414. Pubmed Central PMCID: PMC6257151.

4. Simon GI, Craswell A, Thom O, Fung YL. Outcomes of restrictive versus liberal transfusion strategies in older adults from nine randomised controlled trials: a systematic review and meta-analysis. Lancet Haematol. 2017 Oct;4(10): e465-e474. PubMed PMID: 28919087.

5. Whiting DR, Gillette BP, Duncan C, et al. Preliminary results suggest tranexamic acid is safe and effective in arthroplasty patients with severe comorbidities. Clin Orthop Relat Res. 2014 Jan;472(1):66-72. PubMed PMID: 23817754. Pubmed Central PMCID: PMC3889421.

6. Pitocco C, Sexton TR. Alleviating blood shortages in a resource-constrained environment. Transfusion. 2005 Jul;45(7):1118-1126. PubMed PMID: 15987356.

7. Moskal JT, Harris RN, Capps SG. Transfusion cost savings with tranexamic acid in primary total knee arthroplasty from 2009 to 2012. J Arthroplast. 2015 Mar;30(3):365-368. PubMed PMID: 25458093.

8. Waldow T, Szlapka M, Haferkorn M, et al. Prospective clinical trial on dosage optimizing of tranexamic acid in non-emergency cardiac surgery procedures. Clin Hemorheol Microcirc. 2013 Jan 1;55(4):457-468. PubMed PMID: 24113504.

9. Gillette BP, DeSimone LJ, Trousdale RT, et al. Low risk of thromboembolic complications with tranexamic acid after primary total hip and knee arthroplasty. Clin Orthop Relat Res. 2013 Jan;471(1):150-154. PubMed PMID: ISI: 000312716400022 . English.

10. Bokesch PM, Szabo G, Wojdyga R, et al. A phase 2 prospective, randomized, double-blind trial comparing the effects of tranexamic acid with ecallantide on blood loss from high-risk cardiac surgery with cardiopulmonary bypass (CONSERV-2 Trial). J Thorac Cardiovasc Surg. 2012 May;143(5):1022-1029. PubMed PMID: 21724197. Epub 2011/07/05. eng.

11. Ker K, Edwards P, Perel P, et al. Effect of tranexamic acid on surgical bleeding: systematic review and cumulative meta-analysis. BMJ. 2012 May 17:344. e3054. PubMed PMID: 22611164. Pubmed Central PMCID: PMC3356857.

12. Ker K, Roberts I, Shakur H, Coats TJ. Antifibrinolytic drugs for acute traumatic injury. Cochrane Database Syst Rev. 2015 May 9;5:CD004896. PubMed PMID: 25956410.

13. Ker K, Prieto-Merino D, Roberts I. Systematic review, meta-analysis and metaregression of the effect of tranexamic acid on surgical blood loss. Br J Surg. 2013 Sep;100(10):1271-1279. PubMed PMID: 23839785.

14. Han X, Gong G, Han N, Liu M. Efficacy and safety of oral compared with intravenous tranexamic acid in reducing blood loss after primary total knee and hip arthroplasty: a meta-analysis. BMC Muscoskelet Disord. 2018 Dec 3;19(1):430. PubMed PMID: 30509227. Pubmed Central PMCID: PMC6278110.

15. Zhu Q Yu C, Chen X, et al. Efficacy and safety of tranexamic acid for blood salvage in intertrochanteric fracture surgery: a meta-analysis. Clin Appl Thromb Hemost. 2018 Nov;24(8):1189-1198. PubMed PMID: 29929380.

16. Fusca L, Perelman I, Fergusson D, et al. The effectiveness of tranexamic acid at reducing blood loss and transfusion requirement for women undergoing myomectomy: a systematic review and meta-analysis. J Obstet Gynaecol Can 2018 Oct 29. https://doi.org/10.1016/j.jogc.2018.04.007 [Epub ahead of print] PubMed PMID: 30385210.

17. Shakur H, Roberts I, Bautista R, et al. Effects of tranexamic acid on death vascular occlusive events, and blood transfusion in trauma patients with significant haemorrhage (CRASH-2): a randomised, placebo-controlled trial. Lancet. 2010 Jul 3;376(9734):23-32. PubMed PMID: 20554319. Epub 2010/06 18. eng.

18. Smith SR, Murray D, Pockney PG, et al. Tranexamic acid for lower GI hemorrhage: a randomized placebo-controlled clinical trial. Dis Colon Rectum. 2018 Jan;61(1):99-106. PubMed PMID: 29215478.

19. Kim Y, Amini N, Gani F, et al. Age of transfused blood impacts perioperative outcomes among patients who undergo major gastrointestinal surgery. Ann Surg. 2017 Jan;265(1):103-110. PubMed PMID: 28009733.

20. Larson DW, Lovely JK, Cima RR, et al. Outcomes after implementation of a multimodal standard care pathway for laparoscopic colorectal surgery. $\mathrm{Br}$ Surg. 2014 Jul;101(8):1023-1030. PubMed PMID: 24828373. Epub 2014/05/16.

21. Firth d. Bias reduction of maximum likelihood estimates. Biometrika. 1993;80 $27-38$

22. Shorr AF, Duh MS, Kelly KM, et al. Red blood cell transfusion and ventilatorassociated pneumonia: a potential link? Crit Care Med. 2004 Mar;32(3): 666-674. PubMed PMID: 15090945.

23. Goodnough LT. Risks of blood transfusion. Crit Care Med. 2003 Dec;31(12 Suppl):S678-S686. PubMed PMID: 14724466.

24. Goodnough LT, Panigrahi AK. Blood transfusion therapy. Med Clin. 2017 Mar:101(2):431-447. PubMed PMID: 28189180.

25. Lundin ES, Johansson T, Zachrisson $\mathrm{H}$, et al. Single-dose tranexamic acid in advanced ovarian cancer surgery reduces blood loss and transfusions: doubleblind placebo-controlled randomized multicenter study. Acta Obstet Gynecol Scand. 2014 Apr;93(4):335-344. PubMed PMID: 24428857.

26. Murkin JM, Falter F, Granton J, et al. High-dose tranexamic Acid is associated with nonischemic clinical seizures in cardiac surgical patients. Anesth Analg. 2010 Feb 1;110(2):350-353. PubMed PMID: 19996135.

27. Dzik WH. Emily Cooley Lecture 2002: transfusion safety in the hospital. Transfusion. 2003 Sep;43(9):1190-1199. PubMed PMID: 12919420.

28. Henry DA, Carless PA, Moxey AJ, et al. Anti-fibrinolytic use for minimising perioperative allogeneic blood transfusion. Cochrane Database Syst Rev. 2011 Mar 16;(3):CD001886. PubMed PMID: 21412876. Pubmed Central PMCID: PMC4234031. 